\title{
An In Vivo Microperfusion Study of Distal Tubule Bicarbonate Reabsorption in Normal and Ammonium Chloride Rats
}

\author{
David Z. Levine
}

With statistical analyses by J. Rochon, R. Jones, and S. Raman

and with the technical assistance of M. lacovitti, A. M. Matiz, P. Mills, and L. A. Nash

Departments of Medicine, Physiology, and Epidemiology and Community Medicine, University of Ottawa, Ontario, Canada K1H 8 M5

\begin{abstract}
For many years it has been thought that distal nephron hydrogen ion secretion can be importantly modulated by factors such as sodium delivery, sodium avidity, and potassium stores. Free flow micropuncture studies have also indicated that the rate of bicarbonate delivery may also alter the rate of bicarbonate reabsorption. The present studies were undertaken to examine possible luminal influences on total $\mathrm{CO}_{2}$ reabsorption in microperfused distal tubules in the rat in vivo. Tubules from normal and acidotic rats were perfused with five solutions in a manner that induced changes in bicarbonate load, sodium and potassium fluxes $\left(\mathbf{J}_{\mathrm{Na}}, \mathbf{J}_{\mathrm{K}}\right)$, and luminal sulfate concentration. In each collected perfusate, simultaneous analyses were undertaken to determine water reabsorption, $\mathrm{Na}$, and $\mathrm{K}$ concentrations using graphite furnace atomic absorption spectroscopy and total $\mathrm{CO}_{2}$ by microcalorimetry. Using factorial analysis of covariance to account for confounding effects on total $\mathrm{CO}_{2}$ flux $\left(J_{\mathrm{tCO}_{2}}\right)$ such as water reabsorption, distal tubules of acidotic rats reabsorbed $\mathrm{CO}_{2}$ in the range of $50-112 \mathrm{pmol} \cdot \mathrm{min}^{-1} \cdot \mathrm{mm}^{-1}$. These $\mathrm{J}_{\mathrm{tCO}_{2}}$ values were not significantly correlated with $\mathrm{HCO}_{3}$ load, $\mathbf{J}_{\mathbf{N}_{\mathbf{n}}}$, or $\mathbf{J}_{\mathbf{K}}$ despite changes in the latter from net reabsorption to net secretion. Distal tubules of rats with normal acid-base status had $\mathbf{J}_{\mathrm{tCO}_{2}}$ values which were neither significantly different from zero nor correlated with changes in $\mathbf{J}_{\mathbf{K}}$ and $\mathbf{J}_{\mathbf{N a}}$. Further, doubling the load from 250-500 pmol/min (by doubling the perfusion rate of $25-\mathrm{mM} \mathrm{HCO}_{3}$ solutions) did not stimulate $\mathrm{J}_{\mathrm{ICO}_{2}}$ in these normal animals. Accordingly, these acute in vivo microperfusion studies indicate for the first time that neither load nor potassium or sodium fluxes are important modulators of distal tubule bicarbonate reabsorption.
\end{abstract}

\section{Introduction}

For more than $30 \mathrm{yr}$, it has been thought that renal $\mathrm{H}^{+}$ secretion may depend on $\mathrm{Na}$ and $\mathrm{K}$ transport. The cation exchange hypothesis first proposed by Pitts and Alexander (1) and then by Berliner et al. (2) was modified by Schwartz and his coworkers (3) to explain observations on chronic acid-base disturbances. It was suggested that distal nephron hydrogen ion secretion is modulated by luminal factors such as distal

Portions of this work have appeared in abstract form: Kidney Int. 1983. 23:235.

Address correspondence to Dr. Levine.

Received for publication 13 April 1984 and in revised form 17 August 1984.

J. Clin. Invest.

(c) The American Society for Clinical Investigation, Inc. 0021-9738/85/02/0588/08 \$1.00

Volume 75, February 1985, 588-595
$\mathrm{Na}$ delivery, $\mathrm{Na}$ avidity, and anion effects. Perhaps the most provocative aspect of this view was the specific denial that blood $\mathrm{pH}$ is a regulator of hydrogen ion secretion.

There are, of course, many studies which have attempted to define factors which may regulate distal nephron hydrogen ion secretion and which bear on the proposals noted above. For example, volume expansion has been considered to suppress hydrogen ion secretion while extracellular fluid (ECF) ${ }^{1}$ volume contraction enhances it $(4,5)$. The load of bicarbonate presented to reabsorptive sites was considered to be a "key" factor in determining hydrogen ion secretion and bicarbonate reabsorption in micropuncture studies on rat distal tubules (6). Evidence from direct studies on the papillary collecting duct of the rat also indicates that bicarbonate load importantly determines its reabsorptive rate (7). Finally, potassium handling has been suggested to be another regulator: potassium loading in dogs increases $\mathrm{K}$ secretory fluxes and suppresses the rate of distal nephron hydrogen ion secretion (4). However, in rat distal tubule micropuncture studies, no evidence of a reciprocal relationship between distal tubular $\mathrm{K}$ and hydrogen ion secretory rates could be obtained (8).

The present studies were initiated in the context of the foregoing reports. Bearing in mind that ECF volume, bicarbonate load, and potassium and sodium fluxes $\left(\mathrm{J}_{\mathrm{K}}, \mathrm{J}_{\mathrm{Na}}\right)$ might play a role in hydrogen ion secretion of the distal nephron, we undertook to directly study in the rat the portion of the distal tubule accessible to micropuncture. Our specific objective was to test the hypothesis that distal tubule bicarbonate reabsorption, measured as total $\mathrm{CO}_{2}$ flux $\left(\mathrm{J}_{\mathrm{tCO}_{2}}\right)$, is linked either to bicarbonate load or $\mathrm{J}_{\mathrm{K}}, \mathrm{J}_{\mathrm{Na}}$. By in vivo microperfusion, we changed both the flow rate and composition of the perfusion fluid without alteration in ECF volume. In each collection of the perfusate we measured simultaneously $\mathrm{J}_{\mathrm{tCO}_{2}}, J_{\mathrm{K}}$, and $\mathrm{J}_{\mathrm{Na}}$. Our results from normal and $\mathrm{NH}_{4} \mathrm{Cl}$ acidotic rats indicate that the normal rat distal tubule does not reabsorb $\mathrm{CO}_{2}$ significantly, and this cannot be enhanced by either doubling the $\mathrm{CO}_{2}$ load or altering $J_{\mathrm{Na}}$ or $\mathrm{J}_{\mathrm{K}}$ by perfusate changes. $\mathrm{NH}_{4} \mathrm{Cl}$ acidotic rats, in contrast, have distal tubules which consistently show positive $\mathrm{J}_{\mathrm{tCO}_{2}}$ values, and which cannot be suppressed by either reduction in load or by inducing wide swings in $J_{K}$ or $J_{\mathrm{Na}}$. Accordingly, distal tubule $\mathrm{J}_{\mathrm{tCO}_{2}}$ does not appear to be linked to these luminal factors. Rather, at least for the case of $\mathrm{NH}_{4} \mathrm{Cl}$ rats, distal tubule $\mathrm{J}_{\mathrm{tCO}_{2}}$ may be responsive to the low $\mathrm{pH}$ of systemic blood, or to changes in the cytoplasm of renal tubular cells.

1. Abbreviations used in this paper: ANOVA, analysis of variance; BP, blood pressure; BW, body weight; ECF, extracellular fluid; FANCOVA, factial analysis of covariance; FE, flame emission; GFR, glomerular filtration rate; GFAAS, graphite furnace atomic absorption spectroscopy; $J_{K}$, potassium flux; $J_{\mathrm{Na}}$, sodium flux; $J_{\mathrm{tCO}_{2}}$, total $\mathrm{CO}_{2}$ flux; $\dot{\mathrm{V}}$, initial and collected tubular fluid flow rate; $\mathrm{J}_{\mathrm{H}_{2} \mathrm{O}}$, water flux. 


\section{Methods}

These studies were performed on male Sprague-Dawley rats weighing $\sim 300 \mathrm{~g}$. The animals were bred and raised in climate-controlled facilities at the University of Ottawa. The rats were allowed free access to water and food (Rat Chow 5012, Ralston Purina of Canada, Ltd., Whitby, Ontario, Canada) until the time of experimentation. The rats were anesthetized with $100 \mathrm{mg} / \mathrm{kg}$ Inactin (BYK, Gulden Konstanz, Federal Republic of Germany) and prepared for micropuncture as previously described (9).

\section{Experimental design}

Group I experiments. 27 normal and $52 \mathrm{NH}_{4} \mathrm{Cl}$ acidotic rats were studied. Normal animals were infused with $0.9 \% \mathrm{NaCl}$ at $0.5 \% \mathrm{BW} / \mathrm{h}$. Rats were made acidotic by a single gavage of $4 \mathrm{meq} / 100 \mathrm{~g} \mathrm{BW} \mathrm{NH} \mathrm{Cl}_{4}$ $18 \mathrm{~h}$ before the micropuncture experiment. These animals were then infused at the rate of $3 \% \mathrm{BW} / \mathrm{h}$ with $0.9 \% \mathrm{NaCl}$ to which $50 \mathrm{meq} / \mathrm{l}$ $\mathrm{HCl}$ was added. Animals so treated were usually acceptable for micropuncture and had low but stable plasma bicarbonate concentrations (see Results), blood pressure (BP) $>100 \mathrm{mmHg}$, and normal whole kidney glomerular filtration rate (GFR).

In this first group of experiments, superficial distal tubules of both normal and acidotic rats were perfused with one of three solutions at either 10 or $20 \mathrm{nl} / \mathrm{min}$, as described below. Each collected sample was analyzed for total $\mathrm{CO}_{2}, \mathrm{Na}, \mathrm{K}$, and inulin concentrations. After microdissection for perfused distal tubule length, $\mathrm{J}_{\mathrm{tCO}_{2}}, \mathrm{~J}_{\mathrm{K}}, \mathrm{J}_{\mathrm{Na}}$, and water fluxes $\left(\mathrm{J}_{\mathrm{H}_{2} \mathrm{O}}\right)$ were determined. The data obtained were treated as 12 individual groups in a $2 \times 2 \times 3$ matrix. This represented normal and acidotic rats, high and low perfusion rates, and three different perfusion solutions. Each solution contained $25 \mathrm{mM} \mathrm{NaHCO}_{3}, 0.12 \%$ lissamine green, and $25 \mu \mathrm{Ci} / \mathrm{ml}$ of inulin-methoxy $3 \mathrm{H}$ (New England Nuclear, Boston, MA). The different solutions in addition contained the following (in mM): solution 1: $95 \mathrm{Na}, 65 \mathrm{Cl}$; solution 2: $95 \mathrm{Na}$, $65 \mathrm{Cl}, 15 \mathrm{~K}, 7.5 \mathrm{SO}_{4}$; and solution 3: $33 \mathrm{Na}, 15 \mathrm{~K}, 7.5 \mathrm{SO}_{4}, 101.5$ urea.

Solution 1 allowed $\mathrm{K}$ secretion to continue with normal reabsorption of $\mathrm{Na}$. Solution 2 was designed to provide a continuing $\mathrm{Na}$ reabsorptive flux while superimposing three factors which might, a priori, be construed to enhance $\mathrm{H}^{+}$secretion. The addition of $\mathrm{K}_{2} \mathrm{SO}_{4}$ would be expected to retard $\mathrm{K}$ secretion (10) and increase the transepithelial voltage (11), thereby enhancing $\mathrm{H}^{+}$secretion, particularly if there was an element of distal $\mathrm{K}^{+}-\mathrm{H}^{+}$competition as already suggested by Pichette et al. (4). The presence of the nonreabsorbable anion $\mathrm{SO}_{4}^{-}$ might also be expected to facilitate $\mathrm{H}^{+}$secretion (3). Solution 3 was chosen to reduce $\mathrm{Na}$ reabsorption in the presence of $\mathrm{K}_{2} \mathrm{SO}_{4}$. Urea was added to provide comparable osmolality with solutions 1 and 2 . The perfused rates used and the $25 \mathrm{mM} \mathrm{HCO}$ content of each solution ensured sufficient sample for the three separate analyses required (total $\mathrm{CO}_{2}, \mathrm{Na}$, and $\mathrm{K}$, inulin), while permitting a favorable hydrogen ion secretory gradient as $\mathrm{HCO}_{3}^{-}$delivery increased from 250-500 $\mathrm{pmol} / \mathrm{min}$.

Group II experiments. A second set of distal tubule perfusion studies was carried out to confirm conclusions derived from the first set of experiments described above. $\mathrm{NH}_{4} \mathrm{Cl}$ acidotic rats, after gavage, as described for group I animals, were subjected to protocols intended to widen the range of $\mathrm{K}$ fluxes as well as to control for the presence of sulfate in solution 2 (above). One group of acidotic rats $(n=7)$ was infused systemically with a solution containing $75 \mathrm{mM} \mathrm{KCl}, 75 \mathrm{mM}$ $\mathrm{NaCl}$, and $15 \mathrm{mM} \mathrm{HCl}$ at $3 \%$ of the $\mathrm{BW} / \mathrm{h}$. Distal tubules of these animals were perfused at the rate of $15 \mathrm{nl} / \mathrm{min}$ using solution 1 as described above. A second group of acidotic rats was infused with $0.9 \% \mathrm{NaCl}$ plus $50 \mathrm{mM} \mathrm{HCl}$ (as for group I experiments described above) but a different microperfusion solution was employed. This microperfusion solution (solution 4) was identical to solution 2 except chloride was substituted for sulfate. The perfusion rate was $15 \mathrm{nl} / \mathrm{min}$.

Microperfusion methods. To improve visualization within the neph- ron, perfusion pipettes were coated with a platinum resin (Matthey Bright platinum, Johnson, Matthey and Co. Ltd., Cresswell Staffordshire, England), baked in a muffle furnace at $350^{\circ} \mathrm{C}$ for $1-2 \mathrm{~h}$, and then ground to 7-8 $\mu \mathrm{m}$ outer diameter.

The perfusion pipette was attached to a servo-regulated microperfusion pump (Hampel type III, Wolfgang Hampel, Frankfurt, Federal Republic of Germany). The microperfusion pump chamber was fitted with a Kulite 1S pressure transducer (Durham Instruments, Pickering, Ontario) which permitted continuous measurement of intratubular pressure during perfusion. The pressure device used in these studies was originally described by Wunderlich and Schnermann (12), and subsequently modified for use during microperfusion by Lohfert et al. (13). The pressure device was calibrated in vitro using a Gauer manometer before and after intratubular pressure measurements. Tip resistance was $0.21 \pm 0.03 \mathrm{mmHg} / \mathrm{nl}$ per min determined in surface fluid $(n=34)$. All measurements were made using a multi-channel Linseis flat-bed recorder which permitted continuous display of perfusion rate and intratubular pressure recordings.

In hundreds of perfusions, we have found this technique of continuous intratubular pressure recordings very useful. We have been able to determine whether intratubular pressure departs from normal both during and between sampling. Although incomplete collections could be obtained despite evidence of stable intratubular pressure values, we have only rarely been able to document adequate collections (i.e., within 10-15\% of nominal perfusion rate) in the presence of wide variations in intratubular pressure. For this reason, samples associated with erratic or very abnormal pressure readings were discarded. Collections that departed from nominal perfusion rates by more than $\sim 15 \%$ were discarded. The microperfusion pump was calibrated in vitro after each pipette mounting by collection of a timed aliquot of perfusate pumped directly into a scintillation vial over the range of 0 $50 \mathrm{nl} / \mathrm{min}$. Such calibrations closely approximated perfusion rates determined in vivo. For a setting of $10 \mathrm{nl} / \mathrm{min}$, in vitro calibration in 50 experiments yielded a value of $9.3 \pm 0.3 \mathrm{nl} / \mathrm{min}$ compared to calculated in vivo perfusion rates of $9.9 \pm 0.2 \mathrm{nl} / \mathrm{min}$ in 74 samples. For $20 \mathrm{nl} / \mathrm{min}$, corresponding values were $19.9 \pm 0.4 \mathrm{nl} / \mathrm{min}$ in 50 experiments vs. in vivo values of $20.4 \pm 0.3 \mathrm{nl} / \mathrm{min}$ in 88 samples. Finally, for settings of $15 \mathrm{nl} / \mathrm{min}$ used in 15 group II experiments noted above, the in vitro values were $15.1 \pm 0.3 \mathrm{nl} / \mathrm{min}$ vs. in vivo values of $14.0 \pm 0.3 \mathrm{nl} / \mathrm{min}$ in 26 samples.

The technique of in vivo microperfusion of distal tubules was similar to that already described by Good and Wright (10). Briefly, using randomly punctured proximal tubules, boluses of lissamine green dye were injected in order to locate surface distal tubules with two or more loops suitable for puncture. Upon identification of such a nephron, the microperfusion pipette was placed in the first distal segment and perfusion was allowed to proceed at a low rate. Then, using a larger bore, castor oil-filled pipette, the late proximal segment of the same nephron was punctured, and over a period of several minutes the loop was filled with castor oil. After microperfusion proceeded for several minutes at the designated rate of 10,15 , or 20 $\mathrm{nl} / \mathrm{min}$, the second segment of the distal tubule was entered with a 6$7 \mu \mathrm{m}$ Sudan stained mineral oil pipette. The mineral oil was equilibrated with Hepes buffer (as was the oil in the microperfusion pipette) so as to attempt to preserve an ambient $\mathrm{pCO}_{2}$ of $\sim 65 \mathrm{mmHg}(14,15)$. Thereafter, sampling took place by careful insertion of an oil block into the distal segment and constant monitoring of intratubular pressure.

After collections were complete, perfused tubules were filled with Microfil (Canton Biomedical, Boulder, $\mathrm{CO}$ ). The kidney was removed from the animal, stored at $4^{\circ} \mathrm{C}$ in saline overnight, and digested in $\mathrm{NaOH}$. After digestion, the microfil cast was photographed, teased free, and total length from perfusion to collection site measured with a calibrated eyepiece micrometer.

\section{Analysis of microperfusion samples}

Volumes of collected samples were determined in constant bore quartz tubing. After total volume was determined, the sample was divided 
into three aliquots for analyses of $\left[{ }^{3} \mathrm{H}\right]$ inulin activity, total $\mathrm{CO}_{2}$, and $\mathrm{Na}$ and $\mathrm{K}$ concentrations. The perfusate was similarly treated.

Total $\mathrm{CO}_{2}$ in perfusate and samples was determined by microcalorimetry (14) using oil equilibrated with a Hepes buffer to attain a $\mathrm{pCO}_{2}$ of $65 \mathrm{mmHg}$ (15). For each analysis, duplicate standards of 15 , $20,25,30$, and $35 \mathrm{mM} \mathrm{NaHCO}{ }_{3}$ were run. The perfusion solution containing $25 \mathrm{mM}$ total $\mathrm{CO}_{2}$ was determined on the same sample tray as the collected samples which were in the range of $\sim 20-30 \mathrm{mM}$. The precision of this method is $\pm 5 \%$.

Graphite furnace atomic absorption spectroscopy (GFAAS) analysis of $\mathrm{Na}$ and $\mathrm{K}$ in micropuncture samples. Concentrations of sodium and potassium in perfusates and tubular fluid samples were determined by GFAAS using the IL 951/655 (Instrumentation Laboratories, Lexington, MA). Our technique was a modification of that described by Good and Wright (10) and Kuntziger et al. (16). In brief, 0.10-0.20-nl aliquots of standards, perfusate, and micropuncture samples were deposited onto a removable microboat. The microboat is a portable pyrolytically coated graphite platform which can be removed and reinserted into a companion graphite cuvette in the furnace atomizer. The sample aliquots were dried at $75^{\circ} \mathrm{C}$, pyrolyzed at 750 and $850^{\circ} \mathrm{C}$, and atomized at $2,000^{\circ} \mathrm{C}$ in the furnace atomizer ( $\mathrm{L} 655$ ). Sodium and potassium were measured simultaneously in the double-beam mode. Potassium was measured at $766.5 \mathrm{~nm}$ and sodium at $589.6 \mathrm{~nm}$. Atomization signals for both $\mathrm{Na}$ and $\mathrm{K}$ were displayed simultaneously on a video tube and the signals of interest recorded on an Axiom EX850 video printer. Repeat determinations were within $3 \%$ coefficient of variation, often $<1 \%$ for both $\mathrm{Na}$ and $\mathrm{K}$.

Standards were prepared as aqueous solutions containing both sodium and potassium chloride in a concentration range appropriate for the sample analyzed. Atomization signals, however, were sensitive to matrix composition, as evident from the major perturbations in atomization signal with alteration of the chemical form of the analyte. It was therefore necessary to evaluate the extent to which standard curves using sodium and potassium chloride would accurately estimate the total $\mathrm{Na}$ and $\mathrm{K}$ in complex matrices.

Complete anion substitutions of chloride with acetate, nitrate, fluoride, citrate, hydroxide, sulfate, phosphate, carbonate, and bicarbonate were carried out for $\mathrm{Na}$ at $90 \mathrm{meq} / \mathrm{liter}$ and $\mathrm{K}$ at $15 \mathrm{meq} / \mathrm{liter}$. Complete substitution of chloride by these anions resulted in characteristic alterations in residence time, appearance time, peak shape, and notably peak height for the sodium atomization signals. Sodium peak heights were consistently higher with all chloride substitutions, ranging from $18 \%$ enhancement for carbonate to $88 \%$ enhancement for both sulfate and phosphate. Peak area, however, was not sensitive to anion substitutions. Phosphate had no effect on peak area sodium signal in agreement with Good and Wright (10). Sulfate showed 7\% suppression, and bicarbonate had variable effects (see below). Potassium signals were not as sensitive to changes in chemical form of the analyte for both peak height and peak area as sodium. Peak area absorbance for $\mathrm{K}$ for all substitutions was identical to $\mathrm{KCl}$ except for carbonate $(+4 \%)$. Peak height absorbance was also insensitive to anion substitutions with the exception of enhancement of sulfate $(+17 \%)$ and phosphate $(+12 \%)$. Peak area absorbance was therefore used to generate calibration curves for both $\mathrm{Na}$ and $\mathrm{K}$ in all analyses.

Validation of the accuracy of $\mathrm{Na}$ and $\mathrm{K}$ determination was undertaken for every set of samples analyzed. Perfusates were analyzed daily by flame emission (FE) and compared with GFAAS analysis. Data for $\mathrm{Na}$ and $\mathrm{K}$ were only acceptable if the relative error (defined as the mean error expressed as a percentage of the accepted value [FE]) was within $3 \%$. Sodium for solution $1(n=28)$ was $95.2 \pm 0.77$ meq/liter by FE compared with $94.6 \pm 0.74 \mathrm{meq} / \mathrm{liter}$ by GFAAS. Solution $2(n=18)$ gave $96.1 \pm 0.30$. meq/liter by $\mathrm{FE}$ for $\mathrm{Na}$ and $14.7 \pm 0.05 \mathrm{meq} / \mathrm{liter}$ for $\mathrm{K}$ by $\mathrm{FE}$ compared with $\mathrm{Na}$ of $95 \pm 0.53$ with $15.3 \pm 0.10 \mathrm{meq} / \mathrm{liter}$ for K. Solution $3(n=16)$ had sodium concentration of $33.0 \pm 0.25 \mathrm{meq} / \mathrm{liter}$ and $14.8 \pm 0.06 \mathrm{meq} / \mathrm{liter}$ for $\mathrm{K}$ determined by FE vs. $33.3 \pm 0.7 \mathrm{meq} / \mathrm{liter}$ for $\mathrm{Na}$ and $14.8 \pm 0.08 \mathrm{meq} / \mathrm{liter}$ for $\mathrm{K}$ by GFAAS. Solution 4 in nine experiments gave $93.4 \pm 0.4 \mathrm{meq} /$ liter $\mathrm{Na}$ and $14.7 \pm 0.05 \mathrm{meq} / \mathrm{liter} \mathrm{K}$ by $\mathrm{FE}$ vs. GFAAS values for $\mathrm{Na}$ and $K$ of $95.0 \pm 0.53 \mathrm{meq} / \mathrm{liter}$ and $14.7 \pm 0.3 \mathrm{meq} / \mathrm{liter}$, respectively.

Extensive studies with simulated samples revealed an effect of bicarbonate on enhancing the sodium signal which was constant over a wide range of sodium concentration (60-150 meq/liter) and varied as a function of the bicarbonate concentration. Insofar as the perfused bicarbonate concentrations and collected concentrations were always within a narrow range, and since the perfusion solution was always analyzed along with unknown samples, the presence of such bicarbonate interference was always detectable by measurement of the perfusion standard. Such interference was corrected by changing the microboat or, on occasion, machine parameters. In short, in our hands, bicarbonate enhancement of the $\mathrm{Na}$ signal was very infrequent, always detectable, and remedied successfully. The precise explanation for such enhancement or its correction continues to elude us.

To preclude other possible interferants that may be endogenous to tubular fluid or collected perfusate, recovery studies were carried out on representative samples. Table I shows the results for recovery of added $\mathrm{Na}$ and $\mathrm{K}$ to five micropuncture samples. Recoveries for sodium varied from 96.6 to $107.7 \%$ while potassium recoveries varied from 96.9 to $101.8 \%$.

\section{Calculations and statistical methods}

The collected tubular fluid flow rate $(\dot{V})$ was determined by measuring total volume and time for collection. The initial perfusion rate $(\hat{V})$ was calculated as the product of $\dot{V}$ and the quotient of the $\left[{ }^{3} \mathrm{H}\right]$ inulin concentration in the sample and in the perfusate. Absolute fluxes were calculated as the difference between load (i.e., $\dot{V}$ times initial concentration of $\mathrm{tCO}_{2}, \mathrm{Na}$, or $\mathrm{K}$ ) and collected amounts (i.e., $\dot{\mathrm{V}}$ times final concentration). Flux values, $\mathrm{J}$, are expressed as $\mathrm{pmol} \cdot \mathrm{min}^{-1} \cdot \mathrm{mm}^{-1}$.

A two-level approach was used for drawing statistical inferences from our data. The first approach used the traditional methods of $t$ testing and simple analysis of variance. The second approach involved more sophisticated statistical techniques to more rigorously assess the many factors in our study which simultaneously could influence the rate of bicarbonate reabsorption.

In group I experiments, the effects of $J_{K}, J_{\mathrm{Na}}$, and $J_{\mathrm{H}_{2} \mathrm{O}}$ were considered to be the principal potential modulators of $\mathrm{J}_{\mathrm{tCO}_{2}}$. Systematic differences in these parameters were assessed with respect to three factors: normal acid-base status vs. systemic metabolic acidosis, perfusion rate of $10 \mathrm{nl} / \mathrm{min}$ vs. $20 \mathrm{nl} / \mathrm{min}$, solutions 1,2 , and 3 . To assess these effects, initially unpaired $t$ testing was used to compare normal vs.

Table I. Recovery of Sodium and

Potassium from Tubular Fluid Samples*

\begin{tabular}{llll}
\hline Sample Na & $\begin{array}{l}\text { Na recovery } \\
\text { after standard } \\
\text { addition }\end{array}$ & Sample K & $\begin{array}{l}\text { K recovery } \\
\text { after standard } \\
\text { addition }\end{array}$ \\
\hline meq/l & $\%$ & meq/l & $\%$ \\
129.8 & $\begin{array}{l}104.7 \pm 1.6 \\
(n=10)\end{array}$ & 4.2 & $\begin{array}{c}99.4 \pm 1.10 \\
(n=10)\end{array}$ \\
50.4 & $96.58 \pm 3.2$ & 8.6 & $\begin{array}{l}100.7 \pm 2.2 \\
(n=4)\end{array}$ \\
88.4 & $(n=4)$ & & $\begin{array}{l}101.8 \pm 1.06 \\
(n=5)\end{array}$ \\
57.8 & $104.2 \pm 1.2$ & 4.7 & $99.8 \pm 4.2$ \\
85.1 & $(n=5)$ & & $(n=5)$ \\
& $99.8 \pm 4.2$ & 1.6 & $96.9 \pm 2.7$ \\
$(n=5)$ & & $(n=5)$ \\
\hline
\end{tabular}

\footnotetext{
* See Methods for details.
} 
acidotic rats as well as flow rate. One-way analysis of variance, followed by the Student-Newman Keul's procedure was used to judge the effect of the three solutions.

Since an important goal of this study was to assess the influence of $\mathrm{J}_{\mathrm{Na}}, \mathrm{J}_{\mathrm{K}}$ and $\mathrm{J}_{\mathrm{tCO}_{2}}$ upon each other, in each of the 12 treatment cells noted above (two conditions of acid-base status times two flow rates times three solutions) partial correlation coefficients between pairs of these measures were generated, each of which were controlled for the other response measures and the effect of water movements. In this fashion, the confounding influences of the factors were accounted for.

Although the techniques just described provided useful insight into relationships underlying our data, they nevertheless failed to fully exploit the potential of our experimental design. As a further step, nine samples were randomly selected from each of the twelve experimental cells, thereby yielding a sample size of 108 observations from the original pool of 163 . The nine observations in each cell generally came from different animals, but occasionally from different tubules within the same animals. Factorial analysis of covariance (FANCOVA) was then used to simultaneously assess the influence of the three experimental factors (acid-base status, flow rate, and solutions) as well as the confounding influence of water movements, sodium, and potassium movements on total $\mathrm{CO}_{2}$ reabsorptive rates (17). As shown in the Results and in the Appendix, the formal analysis of variance table and the cell means as adjusted for the significant covariance are reported.

To confirm the conclusions from group I experiments, additional experiments were done on two further groups of acidotic rats (see above). As described above, nine samples were allocated to each cell from this two-group portion of the larger study, and a one-way ANCOVA was used to assess the various effects. Adjusted cell means are also presented for this analysis (see Results).

\section{Results}

Table II summarizes acid-base and electrolyte values in normal and $\mathrm{NH}_{4} \mathrm{Cl}$ acidotic rats with and without systemic $\mathrm{KCl}$ infusions. GFR for normal animals was $1.0 \pm 0.1 \mathrm{ml} / \mathrm{min}$, for $\mathrm{NH}_{4} \mathrm{Cl}$ rats $1.2 \pm 0.1 \mathrm{ml} / \mathrm{min}$, and $1.1 \pm 0.1 \mathrm{ml} / \mathrm{min}$ for $\mathrm{NH}_{4} \mathrm{Cl}$ rats infused with $\mathrm{KCl}$. The $\mathrm{GFR}$ value for $\mathrm{NH}_{4} \mathrm{Cl}$ rats was significantly higher when compared with normal rats $(P$ $<0.05$ ).

Group I experiments. In group I experiments, 91 samples (43 tubules) were taken from $30 \mathrm{NH}_{4} \mathrm{Cl}$ acidotic rats and 73 samples (33 tubules) from 21 normal rats. The corresponding values for $J_{\mathrm{tCO}_{2}}, J_{\mathrm{Na}}$, and $J_{\mathrm{K}}$ are presented in Tables III and IV. Table III shows the raw sample data expressed as the sample mean $\pm S E M$, whereas Table IV shows the covariance

Table II. Acid-Base and Electrolyte Values for Normal and $\mathrm{NH}_{4} \mathrm{Cl}$ Acidotic Rats

\begin{tabular}{lccc}
\hline & $\begin{array}{l}\text { Normal } \\
(n=19)\end{array}$ & $\begin{array}{l}\mathrm{NH}_{4} \mathrm{Cl} \\
\text { acidosis } \\
(n=30)\end{array}$ & $\begin{array}{l}\mathrm{NH}_{4} \mathrm{Cl} \text { acidosis } \\
\mathrm{KCl} \text { loaded } \\
(n=13)\end{array}$ \\
\hline $\mathrm{pH}$ & $7.400 \pm 0.015$ & $7.125 \pm 0.015^{*}$ & $7.039 \pm 0.022 \ddagger$ \\
$\mathrm{pCO}_{2}(\mathrm{mmHg})$ & $45.08 \pm 1.42$ & $35.84 \pm 0.74^{*}$ & $28.34 \pm 1.36 \ddagger$ \\
$\mathrm{HCO}_{3}(\mathrm{meq} / \mathrm{liter})$ & $26.98 \pm 0.44$ & $11.80 \pm 0.43^{*}$ & $7.51 \pm 0.51 \ddagger$ \\
$\mathrm{Na}(m E q /$ liter $)$ & $143.8 \pm 1.0$ & $141.3 \pm 0.50^{*}$ & $140.8 \pm 0.88$ \\
$\mathrm{~K}(m E q /$ liter $)$ & $4.2 \pm 0.10$ & $4.4 \pm 0.10$ & $5.77 \pm 0.29 \ddagger$ \\
$\mathrm{Cl}(\mathrm{mEq} /$ liter $)$ & $105.2 \pm 0.80$ & $124.9 \pm 0.80^{*}$ & $126.0 \pm 0.78$ \\
$\mathrm{Hematocrit}(\%)$ & $46.1 \pm 0.80$ & $48.8 \pm 0.60^{*}$ & $50.5 \pm 1.09$ \\
Protein $(\mathrm{g} / \mathrm{dl})$ & $5.20 \pm 0.05$ & $5.40 \pm 0.08$ & $4.70 \pm 0.17 \ddagger$
\end{tabular}

* $P<0.05$, vs. normal rats (unpaired $t$ test).

$\ddagger P<0.05$, vs. $\mathrm{NH}_{4} \mathrm{Cl}$ acidotic rats (unpaired $t$ test). adjusted mean values which were generated as described in Methods.

In normal rats the mean $\mathrm{J}_{\mathrm{tCO}_{2}}$ values at either 10 or $20 \mathrm{nl} /$ min perfusion rates were not significantly different from 0 by $t$ testing $(P>0.05)$. Acidotic rats, however, showed consistently positive $\mathrm{J}_{\mathrm{tCO}_{2}}$ values at both perfusion rates for the three solutions used. These values were significantly different from $0(P<0.05)$ and are always significantly higher than corresponding values from normal rats $(P<0.05)$ by the unpaired $t$ test. The striking difference between normal and acidotic rats is easily apparent from changes in the total $\mathrm{CO}_{2}$ concentrations. The tubular fluid (TF)/perfusion fluid (PF) $\mathrm{tCO}_{2}$ ratio (TF/pF) was $1.15 \pm 0.11,1.19 \pm 0.05$, and $1.04 \pm 0.04$ for the three solutions in normal rats perfused at $10 \mathrm{nl} / \mathrm{min}$, compared with the corresponding values in acidotic rats of $0.80 \pm 0.05,0.87 \pm 0.08$, and $0.81 \pm 0.04(P<0.01)$ in each instance. Similar values were observed during $20-\mathrm{nl} / \mathrm{min}$ perfusions.

ANOVA testing (Student-Newman Keul) also showed that in both normal and acidotic rats, $\mathrm{J}_{\mathrm{tCO}_{2}}$ values did not differ as a function of solution or flow-rate except for the case of acidotic rats perfused with solution 1 vs. solution 2 at $20 \mathrm{nl} /$ min. $\mathrm{J}_{\mathrm{tCO}_{2}}$ was significantly different $(P<0.05)$. This result was reassessed by FANCOVA as described below. Values for water reabsorption, usually in the range of $1-2 \mathrm{nl}$. $\mathrm{min}^{-1} \cdot \mathrm{mm}^{-1}$, are accounted for as well in the FANCOVA (see below). In order to determine whether $\mathrm{J}_{\mathrm{tCO}_{2}}$ values are affected by changes in perfusion rate or $J_{K}$ or $J_{N a}$, a FANCOVA was undertaken. Confounding variables influencing $\mathrm{J}_{\mathrm{tCO}_{2}}$, particularly water movements, are held constant or accounted for by this technique. The covariance adjusted means (Table IV) show the resulting estimate of $\mathrm{J}_{\mathrm{tCO}_{2}}, \mathrm{~J}_{\mathrm{K}}$, and $\mathrm{J}_{\mathrm{Na}}$ values when simultaneous influences of water movement are held constant. This FANCOVA analysis indicated that neither flow rate nor $\mathbf{J}_{\mathbf{K}}$ or $\mathbf{J}_{\mathrm{Na}}$ significantly influence $\mathbf{J}_{\mathbf{t C O}_{2}}$ in either normal or acidotic rats.

Generation of partial correlation coefficients between $\mathrm{J}_{\mathrm{tCO}_{2}}, J_{\mathrm{K}}$, and $\mathrm{J}_{\mathrm{Na}}$ was also undertaken. This evaluation revealed significant linkage only between $\mathrm{J}_{\mathrm{tCO}_{2}}$ and $\mathrm{J}_{\mathrm{Na}}$ in acidotic rats perfused with solution $2(r=0.60, P<0.01)$ and in the case of $\mathrm{J}_{\mathrm{tCO}_{2}}$ vs. $\mathrm{J}_{\mathrm{K}}$ in normal rats perfused with solution 1 ( $r$ $=0.56, \dot{P}<0.02)$. Note that this significant partial correlative effect occurred in only two of the twelve cells tested. It was of further interest to note that whereas FANCOVA treated the twelve subsets as a group, the partial $r$ analysis treated them individually.

Group II experiments. To confirm the conclusions derived from the group I experiments, namely that neither flow rate nor movements of $\mathbf{J}_{\mathbf{K}}$ or $\mathbf{J}_{\mathrm{Na}}$ influence $\mathbf{J}_{\mathrm{tCO}_{2}}$, additional experiments were undertaken in two groups of acidotic rats. Our attention was specifically devoted to broadening the range of $J_{K}$ and thereby possibly uncovering an effect which might not be detected in the group I experiments. Table $\mathrm{V}$ shows that $\mathrm{J}_{\mathrm{K}}$ in acidotic rats infused with $\mathrm{KCl}$ (solution 1) had higher values for $J_{K}$ than in the previous twelve subsets studied. The perfusate containing $\mathrm{KCl}$ was used to control for effects which may have been engendered by the use of sulfate (solution 2). Thus, with particular reference to different influences on $\mathbf{J}_{\mathbf{K}}$, four separate groups were studied and are presented in Fig. 1, which clearly shows that $J_{\mathrm{tCO}_{2}}$ changes little in the presence of wide swings of $J_{K}$.

As presented for group I experiments, Table $\mathrm{V}$ shows the mean values for samples (mean \pm SEM). These data were also 
Table III. Distal Tubule $\mathrm{tCO}_{2}, \mathrm{~K}$, and $\mathrm{Na}$ Fluxes* in $\mathrm{NH}_{4} \mathrm{Cl}$ and Normal Rats

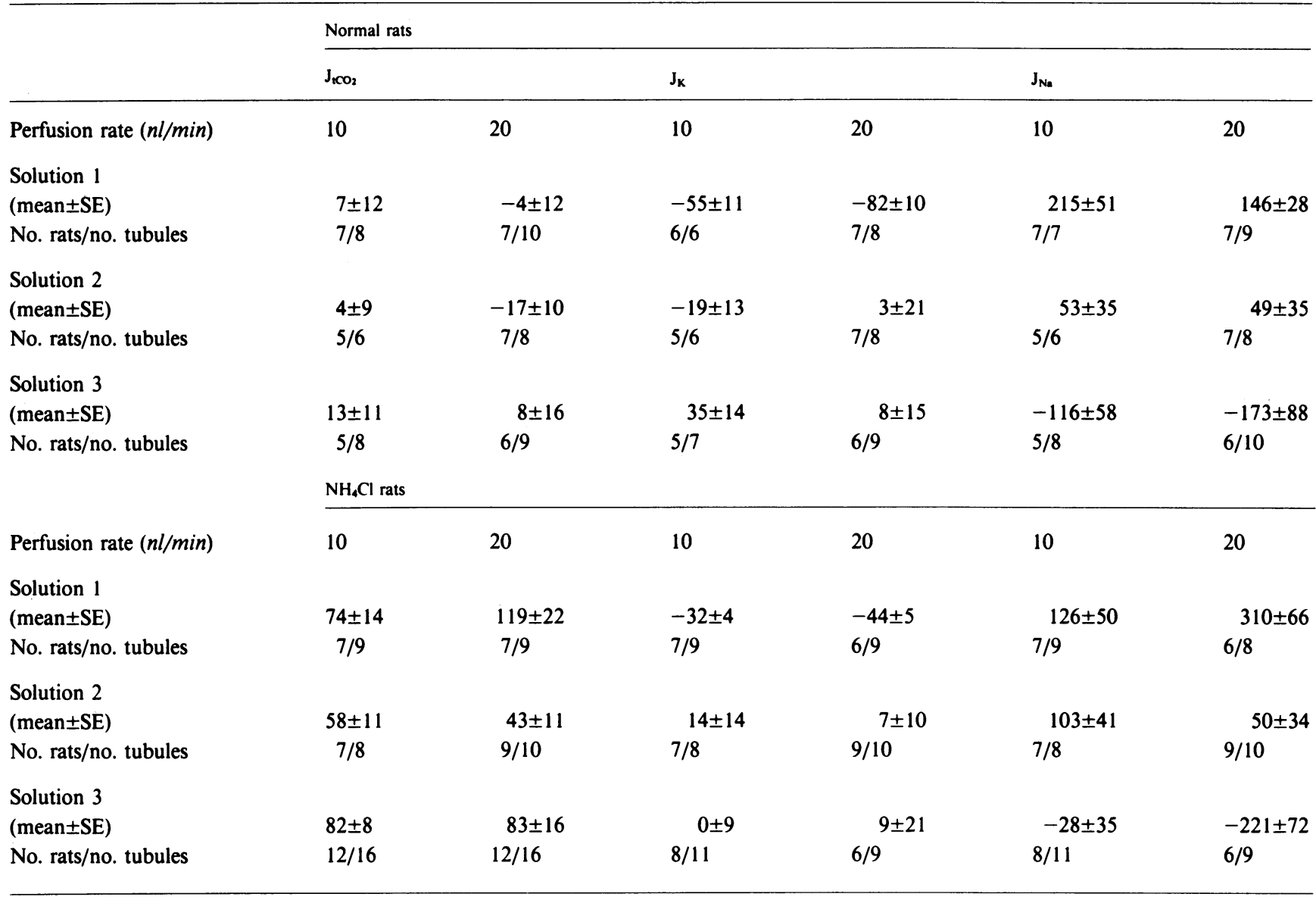

* $\mathrm{pmol} \cdot \mathrm{min}^{-1} \cdot \mathrm{mm}^{-1}$.

tested by FANCOVA using nine samples from each group. The covariance-adjusted mean values for $\mathrm{J}_{\mathrm{tCO}_{2}}, \mathrm{~J}_{\mathrm{K}}$, and $\mathrm{J}_{\mathrm{Na}}$ $\left(\mathrm{pmol} \cdot \mathrm{min}^{-1} \cdot \mathrm{mm}^{-1}\right)$ for acidotic rats infused with $\mathrm{KCl}$ were $53,-118$, and 177 , respectively. Corresponding values for solution 4 were $\mathrm{J}_{\mathrm{tCO}_{2}}=37, \mathrm{~J}_{\mathrm{K}}=48$, and $\mathrm{J}_{\mathrm{Na}}=119$ $\mathrm{pmol} \cdot \mathrm{min}^{-1} \cdot \mathrm{mm}^{-1}$.

\section{Table IV. FANCOVA-adjusted Means for Distal Reabsorption*}

\begin{tabular}{lllrrr}
\hline $\begin{array}{l}\text { Animal } \\
\text { group }\end{array}$ & Perfusate & $\begin{array}{l}\text { Perfusion } \\
\text { rate }\end{array}$ & $\mathrm{J}_{\mathbf{1 C O}_{2}}$ & $\mathrm{~J}_{\mathrm{Na}^{2}}$ & $\mathrm{~J}_{\mathbf{K}}$ \\
\hline Normal rats & Solution 1 & 20 & -1 & 167 & -77 \\
& $(95 \mathrm{Na}, 0 \mathrm{~K})$ & 10 & 11 & 155 & -59 \\
& Solution 2 & 20 & -8 & 61 & -6 \\
& $(95 \mathrm{Na}, 15 \mathrm{~K})$ & 10 & 19 & 85 & -16 \\
& Solution 3 & 20 & 25 & -64 & 17 \\
& $(33 \mathrm{Na}, 15 \mathrm{~K})$ & 10 & 24 & -103 & 35 \\
& & & & & \\
& Solution 1 & 20 & 93 & 321 & -59 \\
& $(95 \mathrm{Na}, 0 \mathrm{~K})$ & 10 & 83 & 102 & -26 \\
& Solution 2 & 20 & 56 & 83 & 12 \\
& $(95 \mathrm{Na}, 15 \mathrm{~K})$ & 10 & 52 & 89 & 12 \\
& Solution 3 & 20 & 112 & -270 & -5 \\
& $(33 \mathrm{Na}, 15 \mathrm{~K})$ & 10 & 78 & -40 & -5 \\
\hline
\end{tabular}

Means for $\mathrm{J}_{\mathrm{iCO}_{2}}, \mathrm{~J}_{\mathrm{Na}}$, and $\mathrm{J}_{\mathrm{K}}$ were adjusted for correlation with $\mathrm{J}_{\mathrm{H}_{2} \mathrm{O}}$. * $\mathrm{pmol} \cdot \mathrm{min}^{-1} \cdot \mathrm{mm}^{-1}$.
Analysis of covariance testing in this fashion revealed no influence of $\mathrm{J}_{\mathrm{K}}$ or $\mathrm{J}_{\mathrm{Na}}$ on $\mathrm{J}_{\mathrm{tCO}_{2}}$. Finally, partial correlation analysis was also undertaken as described above, and no linkage between $\mathrm{J}_{\mathrm{tCO}_{2}}$ and $\mathrm{J}_{\mathrm{Na}}$ or $\mathrm{J}_{\mathrm{K}}$ could be demonstrated.

\section{Discussion}

In these in vivo experiments, we have perfused distal tubules in normal and $\mathrm{NH}_{4} \mathrm{Cl}$ acidotic rats in order to determine if bicarbonate reabsorption measured as total $\mathrm{CO}_{2}$ is linked to intratubular bicarbonate load or fluxes of potassium or sodium. By varying the flow rate and composition of the perfusion solution, we have been able to induce changes in bicarbonate load as well as in $\mathbf{J}_{\mathbf{K}}$ and $\mathbf{J}_{\mathrm{Na}}$. Simultaneous measurement of these three fluxes in each of 189 samples from five experimental groups enabled us to draw the following conclusions: (a) changing $J_{K}$ and $J_{\mathrm{Na}}$ in distal tubules of normal rats does not stimulate $\mathrm{J}_{\mathrm{tCO}_{2}} ;(b)$ in $\mathrm{NH}_{4} \mathrm{Cl}$ acidotic animals, where significant $\mathrm{J}_{\mathrm{tCO}_{2}}$ is consistently demonstrated, reversal of $\mathrm{J}_{\mathrm{K}}$ and $\mathrm{J}_{\mathrm{Na}}$ does not suppress this reabsorptive activity; (c) doubling of the load of bicarbonate perfused does not influence the $\mathrm{J}_{\mathrm{tCO}_{2}}$ of normal or $\mathrm{NH}_{4} \mathrm{Cl}$ acidotic rats. Accordingly, our in vivo direct measurements show for the first time that neither load nor potassium or sodium fluxes are important modulators of distal tubule bicarbonate reabsorption.

At the outset, it is very important to review some difficult statistical issues which we encountered in analyzing the present 
Table V.* Distal Tubule Total $\mathrm{tCO}_{2}, \mathrm{~K}$, and $\mathrm{Na}$ Fluxes $\ddagger$ in $\mathrm{NH}_{4} \mathrm{Cl}$ Acidotic Rats§

\begin{tabular}{|c|c|c|c|c|}
\hline & \multicolumn{4}{|l|}{$15 \mathrm{nl} / \mathrm{min}$} \\
\hline & & $\mathrm{J}_{\mathrm{KCO}_{2}}$ & $\mathbf{J}_{\mathbf{k}}$ & $\mathrm{J}_{\mathrm{N}}$ \\
\hline \multirow[t]{2}{*}{ Solution 1 plus systemic $\mathrm{KCl}$ infusion } & Mean \pm SEM & $57 \pm 8$ & $-112 \pm 21$ & $175 \pm 32$ \\
\hline & No. rats/no. tubules & $7 / 10$ & $7 / 10$ & $7 / 10$ \\
\hline \multirow[t]{2}{*}{ Solution 4} & Mean \pm SEM & $40 \pm 8$ & $50 \pm 26$ & $127 \pm 38$ \\
\hline & No. rats/no. tubules & $7 / 9$ & $7 / 9$ & $7 / 9$ \\
\hline
\end{tabular}

* See also text for details. $\ddagger \mathrm{pmol} \cdot \mathrm{min}^{-1} \cdot \mathrm{mm}^{-1}$. $\S$ Group 2 experiments.

data. We have already been acutely aware of various statistical problems inherent in the design of micropuncture experiments. In previous publications, we have drawn attention to the mandatory use of appropriate ANOVA techniques as well as the use of partial correlation analysis $(18,19)$. Thus, in the present study, as in many other micropuncture investigations, the questions asked involve the allocation of an effect of one parameter or perturbation upon another measured parameter. In the present experiments, our specific question can be simply restated as follows: "Are distal tubule total $\mathrm{CO}_{2}$ fluxes linked with changes in sodium or potassium fluxes?" We have already shown how changes in mean values in different protocols and significance of simple correlation coefficients cannot answer such a question when there are confounding variables such as changes in water reabsorption, perfusion rates, and different experimental protocols (19). As discussed in detail in Methods and Results, an initial factorial analysis of variance matrix was developed using 12 different sets which derived from normal and acidotic rats perfused at two flow rates using three different perfusates. In a separate analysis, to confirm the conclusions of the first set of experiments, the results of a second group of experiments using two further protocols were also analyzed. Factorial analysis of variance indicated that when $\mathbf{J}_{\mathrm{H}_{2} \mathrm{O}}$, which strongly influenced movements of $\mathrm{J}_{\mathrm{tCO}_{2}}, \mathrm{~J}_{\mathrm{Na}}$, and $\mathrm{J}_{\mathrm{K}}$, was accounted for, there was no demonstrable effect on $\mathrm{J}_{\mathrm{tCO}_{2}}$ induced by either changing the load of perfused bicarbonate or the five different protocols employed. The subsequent evaluation of partial correlation coefficients (partial $r$ ) generally confirmed this overall finding. That is, with the exception of a significant partial $r$ of $\mathrm{J}_{\mathrm{tCO}_{2}}$ and $\mathrm{J}_{\mathrm{K}}$ in normal rats using the high sodium zero $\mathrm{K}$ solution, and in acidotic rats of $\mathrm{J}_{\mathrm{tCO}_{2}}$ and

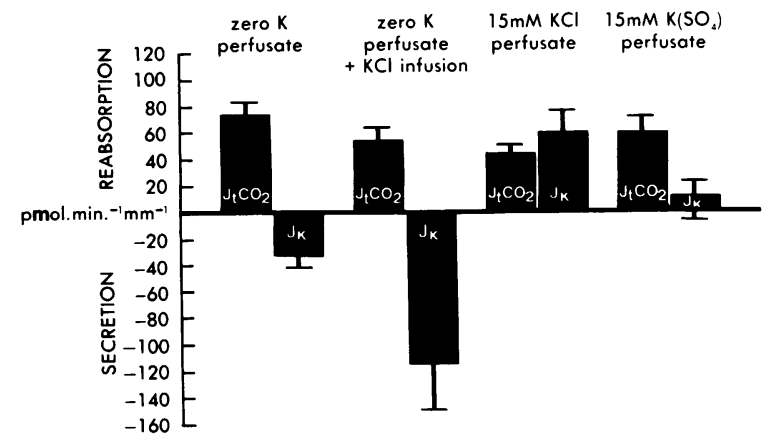

Figure 1. $\mathrm{J}_{1 \mathrm{CO}_{2}}$ and $\mathrm{J}_{\mathrm{K}}$ values during distal tubule in vivo perfusion in four experimental settings. Shown are mean values \pm SEM.
$\mathbf{J}_{\mathrm{Na}}$ using the $\mathrm{K}$ sulfate-containing solution, partial $r$ values were not found to be significant in any of the other 12 cells tested. Thus, in view of the very wide swings of potassium and sodium fluxes we intentionally induced, these rigorous tests of statistical significance strongly support the conclusion that $\mathrm{J}_{\mathrm{tCO}_{2}}$ is not importantly linked with $\mathrm{J}_{\mathrm{Na}}$ and $\mathrm{J}_{\mathrm{K}}$ or with bicarbonate load.

The most important finding of our studies is the demonstration, in vivo, that rat distal tubule bicarbonate reabsorption is seemingly uninfluenced by the bicarbonate load or by changes of $\mathrm{J}_{\mathrm{Na}}$ and $\mathrm{J}_{\mathrm{K}}$ from net reabsorption to net secretion. It is appropriate to consider this result with regard to the following issues: anatomic heterogeneity of the distal tubule; acidification characteristics of distal nephron segments other than the distal tubule; anion effects; effects of bicarbonate load; and the non-homeostatic hypothesis (3) of renal acidification.

Anatomic heterogeneity of the distal tubule. Of course, it has been long recognized (20) that the distal tubule of the rat is composed of different types of epithelium. The distal tubule on the surface of the kidney that confronts the micropuncturist is known to be composed of epithelium of the distal convoluted tubule, the connecting tubule, and of the initial collecting tubule. As already noted by Lucci et al. (15), this anatomic heterogeneity could contribute to the variability of bicarbonate reabsorptive rates measured in normal rats and rabbits. Since it is possible that the mitochondria-rich intercalated cells found in the initial collecting tubule may secrete protons (20), the length of such epithelium traversed by our perfusions could influence the observed rate of bicarbonate reabsorption. It is important to appreciate that in the present studies no attempt was made to perfuse either early or late surface distal tubule segments. Rather, the length and location of the perfused epithelium was dictated only by the presence of two surface loops (see Methods) and the convenience of placement of perfusion and collection pipettes. There can be no doubt, therefore, that the 189 samples that comprise the present study must have derived from distal tubule segments which were composed of both initial collecting tubule epithelium as well as "true" early distal convoluted tubule epithelium (20). It appears reasonable to conclude that whatever the intimate mechanisms of proton secretion in surface distal tubules, the present studies almost certainly reflect the combined contributions of different epithelial types to acidification in the face of changes in bicarbonate load, $\mathbf{J}_{\mathrm{Na}}$, and $\mathrm{J}_{\mathrm{K}}$ (see below).

Acidification characteristics of distal nephron segments other than the distal tubule. Recently, several important in 
vitro studies have been reported which have specifically addressed the sodium dependency of acidification of distal nephron segments. The study of Laski and Kurtzman (21) has provided evidence that $\mathrm{CO}_{2}$ reabsorption by the cortical collecting tubule is consistent with a model of electrogenic acidification that is dependent on a luminal potential generated by sodium transport. Some sodium dependence of acidification by the cortical collecting tubule using another technique has also been shown by Koeppen and Helman (22). These suggestions of sodium-dependent cortical collecting tubule acidification are in contrast to the earlier work of McKinney and Burg (23). McKinney and Burg (23) and Lombard et al. (24) have also reported that the cortical collecting tubule appears to reabsorb more bicarbonate during in vitro studies when the antemortem state of the animal was acidosis. Other studies (Laski and Kurtzman [21], Lombard et al. [24], and Stone et al. [25]) seem to agree that direct sodium dependency is not demonstrable in the rather brisk acidification of the medullary collecting tubule. Finally, in vivo reports involving the inner medullary collecting duct did not demonstrate an obvious link between hydrogen ion secretion and sodium or potassium movements $(26,27)$. How, then, do the present distal tubule studies fit in with these other reports? At the outset, it must be understood that in no sense should our results on distal tubules be interpreted to mean that the $\mathrm{CO}_{2}$ reabsorptive rates we observed in $\mathrm{NH}_{4} \mathrm{Cl}$ rats are sodium-independent in a strict transport sense. Our protocols did not involve lowering the luminal sodium concentration below $33 \mathrm{mM}$, nor was there any manipulation of the peritubular sodium concentration. Thus, our experiments were not intended to demonstrate a sodium or potassium limitation of net acidification by the distal tubule. Rather, what our studies do show is that over a wide range of sodium and potassium concentrations in the perfusate, and subsequent major alterations of net flux (for $\mathbf{J}_{\mathrm{Na}},+321 \mathrm{pmol} \cdot \mathrm{min}^{-1} \cdot \mathrm{mm}^{-1}$ to $-270 \mathrm{pmol} / \mathrm{min}$ per $\mathrm{mm}$; for $\mathrm{J}_{\mathrm{K}},-112 \mathrm{pmol} \cdot \mathrm{min}^{-1} \cdot \mathrm{mm}^{-1}$ to $+50 \mathrm{pmol} / \mathrm{min}$ per $\mathrm{mm}$ ), $\mathrm{J}_{\mathrm{tCO}_{2}}$ continued to be brisk and seemingly uninfluenced by such flux changes (Tables IV and V). Accordingly, we conclude, based on the simultaneous measurement of $\mathrm{J}_{\mathrm{tCO}_{2}}, \mathrm{~J}_{\mathrm{Na}}$, and $\mathrm{J}_{\mathrm{K}}$ of distal tubule samples in vivo, that there cannot be tightly coupled $\mathrm{Na}-\mathrm{H}$ or $\mathrm{K}-\mathrm{H}$ secretion in a net sense. Other in vitro distal tubule perfusions or in vivo simultaneous luminal and peritubular perfusions, perhaps with the use of amiloride and ouabain, could more completely characterize the mechanism of acidification.

Anion effects. In the present studies, in eight experiment subgroups, sulfate was substituted for chloride. Thus, in solution 2 there is partial substitution of sulfate for chloride in the presence of a sodium concentration in the perfusate of 93 mM. In solution 3 , sulfate was completely substituted for chloride while perfusate sodium concentration was $33 \mathrm{mM}$ and potassium concentration was such as to prevent $\mathrm{K}$ secretion. These substitutions at high and low flow in both normal and acidotic animals did not reveal an obvious effect on $\mathrm{J}_{\mathrm{tCO}_{2}}$. Notwithstanding this result, it is clear that to completely exclude anion effects it would be important not only to study other anions such as gluconate, cyclamate, and tetramethylammonium, but also to conduct substitutions with other permutations of high and low sodium concentrations in the perfusate.
Effects of bicarbonate load. As already noted, doubling of the perfused bicarbonate load from 250 to $500 \mathrm{pmol} / \mathrm{min}$ could not elicit an enhancement of bicarbonate reabsorption in normal animals, nor alter the brisk rate of reabsorption in acidotic rats. The perfusions used contained $\sim 25 \mathrm{mM}$ bicarbonate, which facilitated measurement of tubular fluid total $\mathrm{CO}_{2}$ concentration and made unlikely a gradient limitation to proton secretion. We recognize that lower rates of bicarbonate perfusion $(<250 \mathrm{pmol} / \mathrm{min})$ or lower luminal concentrations of bicarbonate could reveal an effect of perfused load on $\mathrm{J}_{\mathrm{tCO}_{2}}$ if the present results in fact represent saturation of the proton secretory rate in acidotic animals. In any case, contrary to previous reports (6), at least in the 12 experimental subsets studied by us, load was not a regulator of $\mathrm{J}_{\mathrm{tCO}_{2}}$.

The non-homeostatic hypothesis (3) of renal acidification. In the Introduction we have drawn attention to the early views of renal acidification and those more recently and elegantly presented by Schwartz and Cohen (3). The non-homeostatic theory of acidification specifically denies that $\mathrm{pH}$ is an important determinant of hydrogen ion secretion, but rather sodium delivery and sodium reabsorption by sodium "avid" reabsorbing sites is the principal modulator of acidification. It must be stressed that the experiments which led to the formulation of this theory by Schwartz and his colleagues (3) have been, in our view, impeccably executed and reasonably interpreted. These studies, usually of chronic duration in unanaesthetized dogs and humans, stand in contrast to the present acute perfusion experiments which did not involve changes in sodium avidity, total body potassium stores, extracellular fluid volume, chloride balance, etc. Further, the views of Schwartz and Cohen (3) of necessity were not extended to provide predictions of the acidification characteristics of discrete segments that comprise the distal nephron. Rather, their proposals have drawn attention, in a seemingly satisfactory fashion, to a possible central role for sodium reabsorption in explaining long-term chronic steady state adjustments by the whole kidney. Thus, the present in vivo distal tubule perfusion studies cannot be construed as a test of these views. Rather, the significance of our findings is that for the first time in vivo, a portion of the distal nephron-the distal tubule composed of several types of epithelium (see above) — can be made to drastically alter the magnitude and direction of net sodium and potassium transport without, seemingly, importantly modulating bicarbonate reabsorption. Thus, in acidotic rats where bicarbonate reabsorption is brisk, net sodium secretion did not impair simultaneous bicarbonate reabsorption, whereas in normal animals where bicarbonate reabsorption is difficult to demonstrate, vigorous sodium reabsorption plus partial or complete substitution of sulfate with chloride (thought to favor hydrogen ion secretion by the non-homeostatic theory) was not associated with enhanced bicarbonate reabsorption. A more definitive test of the non-homeostatic hypothesis must involve experiments on tubules from animals subjected to the chronic disturbances studied so successfully by Schwartz and his colleagues (3).

In summary, we have undertaken in vivo distal tubule microperfusion experiments in normal and $\mathrm{NH}_{4} \mathrm{Cl}$ acidotic rats. We have been able to show for the first time that the brisk $\mathrm{J}_{\mathrm{tCO}_{2}}$ reabsorption by distal tubules of acidotic rats is unresponsive to major changes in $\mathbf{J}_{\mathbf{N a}}, \mathbf{J}_{\mathbf{K}}$, or bicarbonate load induced by in vivo luminal perfusion. 
Appendix

FANCOVA table for $\mathrm{J}_{\mathrm{ICO}_{2}}$ as dependent variable*

\begin{tabular}{lcrrrr}
\hline Source & Sum of squares & Degrees of freedom & Mean square & F & Tail probability \\
\hline pH level & 114742.11 & 1 & 114742.11 & 49.83 & 0.000 \\
Solution & 15900.47 & 2 & 7950.23 & 3.45 & 0.036 \\
Flow-rate & 71.04 & 1 & 71.04 & 0.03 & 0.861 \\
pH level $\times$ solution & 5483.98 & 2 & 2741.94 & 1.19 & 0.309 \\
pH level $\times$ flow-rate & 5406.76 & 1 & 5406.76 & 2.35 & 0.129 \\
Solution $\times$ flow-rate & 3942.50 & 2 & 1971.25 & 0.86 & 0.428 \\
pH $\times$ solution $\times$ flow-rate & 160.71 & 2 & 80.35 & 0.03 & 0.966 \\
Covariate $\mathrm{H}_{2} \mathrm{O}$ & 61344.80 & 1 & 61344.80 & 26.64 & 0.000 \\
Error & 218770.43 & 95 & 2302.85 & & \\
Regression coefficient & 16.573 & & & &
\end{tabular}

* See Methods and Results for details.

\section{Acknowledgments}

We are grateful to Dr. H.-U. Gutsche for introducing the elegant technique of continuous intratubular pressure measurements in our laboratory.

This work was supported by Medical Research Council grant MT3836.

\section{References}

1. Pitts, R. F., and R. S. Alexander. 1945. The nature of the renal tubular mechanism for acidifying the urine. Am. J. Physiol. 144:239254.

2. Berliner, R. W., T. J. Kennedy, Jr., and J. G. Hilton. 1950. Renal mechanisms for excretion of potassium. Am. J. Physiol. 162:348367.

3. Schwartz, W. B., and J. J. Cohen. 1978. The nature of the renal response to chronic disorders of acid-base equilibrium. Am. J. Med. 64:417-428.

4. Pichette, C., Siu-Cheung Tam, Ching-Bun Chen, M. Goldstein, B. Stinebaugh, and M. Halperin. 1982. Effect of potassium on distal nephron hydrogen ion secretion in the dog. J. Lab. Clin. Med. 100:374-384.

5. Tam, S. C., M. B. Goldstein, R. M. A. Richardson, W. L. M. Robson, B. J. Stinebaugh, and M. L. Halperin. 1980. Effect of extracellular fluid volume contraction on distal-nephron hydrogen ion secretion in vivo. J. Lab. Clin. Med. 96:442-459.

6. Malnic, G., M. de Mello Aires, and G. Giebisch. 1972. Micropuncture study of renal tubular hydrogen ion transport in the rat. $\mathrm{Am}$. J. Physiol. 222:147-158.

7. Richardson, R. M. A., and R. T. Kunau, Jr. 1982. Bicarbonate reabsorption in the papillary collecting duct: effect of acetazolamide. Am. J. Physiol. 243:F74-F80.

8. Malnic, G., M. de Mello Aires, and G. Giebisch. 1971. Potassium transport across renal distal tubules during acid-base disturbances. Am. J. Physiol. 221(4):1192-1208.

9. Levine, D. Z., M. K. Byers, R. A. McLeod, and J. A. Luisello. 1979. Loop of Henle bicarbonate accumulation in vivo in the rat. $J$. Clin. Invest. 63:59-66.

10. Good, D. W., and F. S. Wright. 1979. Luminal influences on potassium secretion: sodium concentration and fluid flow rate. Am. J. Physiol. 236(2):F192-F205.

11. Hayslett, J. P., E. L. Boulpaep, and G. H. Giebisch. 1978. Factors influencing transepithelial potential difference in mammalian distal tubule. Am. J. Physiol. 234(3):F182-F191.

12. Wunderlich, P., and J. Schnermann. 1969. Continuous recording of hydrostatic pressure in renal tubules and blood capillaries by use of a new pressure transducer. Pfluegers Arch. Eur. J. Physiol. 313:89-94.
13. Lohfert, H., I. Lichtenstein, M. Butz, and K. Hierholzer. 1971. Continuous measurement of renal intratubular pressures with a combined pressure transducer microperfusion system. Pfluegers Arch. Eur. J. Physiol. 327:191-202.

14. Vurek, G. G., D. G. Warnock, and R. Corsey. 1975. Measurement of picomole amounts of carbon dioxide by calorimetry. Anal. Chem. 47:765-767.

15. Lucci, M. S., L. R. Pucacco, N. W. Carter, and T. D. DuBose, Jr. 1982. Evaluation of bicarbonate transport in rat distal tubule: effects of acid-base status. Am. J. Physiol. 243:F335-F341.

16. Kuntziger, H., A. Antonetti, S. Couette, C. Coureau, and C. Amiel. 1974. Ultramicro (nanoliter range) determination of calcium concentration $\left(10^{-3} \mathrm{M}\right)$ by atomic absorption. Anal. Biochem. 60:449454.

17. Neter, John, and William Wasserman, editors. 1974. Analysis of covariance for completely randomized designs. In Applied Linear Statistical Models. Richard D. Irwin, Inc., Homewood, IL. 685-718.

18. Levine, D. Z., L. A. Nash, T. Chan, and A. H. E. Dubrovskis. 1976. Proximal bicarbonate reabsorption during Ringer and albumin infusions in the rat. J. Clin. Invest. 57:1490-1497.

19. Raman, S., G. Mousseau, and D. Z. Levine. 1977. Statistical models for renal micropuncture studies. Am. J. Physiol. 233(4):F349F357.

20. Tisher, C. C. 1981. Anatomy of the kidney. In The Kidney. B. M. Brenner and F. C. Rector, Jr., editors. W. B. Saunders Co., Philadelphia. 45-55.

21. Laski, Melvin E., and Neil A. Kurtzman. 1983. Characterization of acidification in the cortical and medullary collecting tubule of the rabbit. J. Clin. Invest. 72:2050-2059.

22. Koeppen, Bruce M., and Sandy I. Helman. 1982. Acidification of luminal fluid by the rabbit cortical collecting tubule perfused in vitro. Am. J. Physiol. 11:F521-F531.

23. McKinney, T. D., and M. B. Burg. 1978. Bicarbonate absorption by rabbit cortical collecting tubules in vitro. Am. J. Physiol. 234(2):F141F145.

24. Lombard, W. E., J. P. Kokko, and H. R. Jacobson. 1983. Bicarbonate transport in cortical and outer medullary collecting tubules. Am. J. Physiol. 244:F289-F296.

25. Stone, D. K., D. W. Seldin, J. P. Kokko, and H. R. Jacobson. 1983. Mineralocorticoid modulation of rabbit medullary collecting duct acidification. J. Clin. Invest. 72:77-83.

26. Graber, M. L., H. H. Bengele, E. Mroz, C. Lechene, and E. A. Alexander. 1981. Acute metabolic acidosis augments collecting duct acidification rate in the rat. Am. J. Physiol. 241:F669-F676.

27. Ullrich, K. J., and F. Papavassiliou. 1981. Bicarbonate reabsorption in the papillary collecting duct of rats. Pfluegers Arch. Eur. J. Physiol. 389:271-275. 